\title{
LA DOCTRINA DE LA VOLUNTARIEDAD EN LA ETICA EUDEMIA
}

\section{THE DOCTRINE OF THE WILLFULNESS IN THE EUDEMIAN ETHICS}

\author{
MARCELLO ZANATTA* \\ Universidad de Calabria
}

RESUMEN: El análisis comparativo de la teoría aristotélica de la voluntariedad muestra que la Ética a Eudemo resume las tesis de la Ética a Nicomaco y las expone de una manera más rigurosa. Así, en este sentido, podríamos considerar que la Ética a Eudemo es posterior a la Ética a Nicómaco.

PALABRAS CLAVE: Aristóteles, voluntariedad.

ABSTRACT: The comparative analysis of the Aristotelian theory on volition shows that Eudemian Ethics summarizes the theses of Nicomachean Ethics and presents them of a more rigorous way. From this aspect Eudemian Ethics seems to have come after Nicomachean Ethics.

KEYWORDS: Aristotle, willfulness.

\section{Introducción}

Como ya hiciera en la Ética nicomáquea, Aristóteles emprende en la Ética eudemia un estudio sobre la voluntariedad, lo que se entiende inmediatamente si tenemos en cuenta que, en general, la investigación que en ella se lleva a cabo

*E-mail: mazanat@tin.it 
tiene como objeto las virtudes, y éstas no tendrían ningún valor si las acciones que les corresponden no fuesen voluntarias.

El mencionado estudio de la Ética eudemia queda precedido por amplios desarrollos que tienen como cometido probar que el hombre es causa y prin-

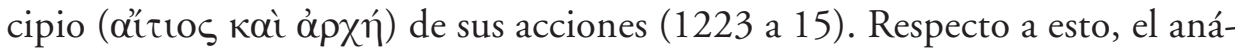
lisis de la voluntariedad quiere especificar las condiciones que están en la raíz de esta tesis, mediante un programa de investigación según el cual, en primer lugar, Aristóteles verifica la tesis mencionada y después indaga a propósito de cuál sea el presupuesto de las situaciones que la misma presenta. Y puesto que, como se establecerá (cfr. Eth. eud., II, 10 e 11), ésta reside en el hecho de que la acción es el resultado de una elección deliberada ( $\pi \rho 0 \alpha i \rho \varepsilon \sigma \iota \varsigma)$ y ésta cae en el ámbito de lo voluntario, del que constituye un caso especial, se justifica la necesidad de indagar cuándo una acción es voluntaria. Desde esta perspectiva, la investigación que prueba que el hombre es causa y principio de sus actos sirve, digámoslo así, de base en la cual se inserta el estudio de la voluntariedad y de la elección deliberada.

\subsection{Secuencia de tesis lógicamente consecuenciales}

Esta investigación se articula según una secuencia de tesis lógicamente consecuenciales sobre las que es necesario detenerse. Después de haber precisado al comienzo de la misma que para esta investigación es necesario asumir

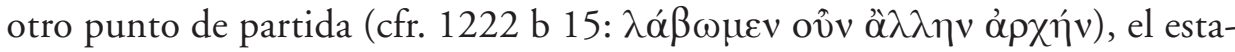
girita afirma que:

— todas las sustancias son por naturaleza principios (1222 b 15-16);

- el hombre es principio, además de en relación a otras sustancias semejantes (es decir, de otros hombres), en relación a las acciones (1222 b 1720);

- principios en sentido preeminente son aquéllos de los cuales derivan los movimientos como de un término primero, y sobre todo aquéllos de los cuales derivan cosas que no pueden ser de otro modo (1222 b 20-23). Por lo tanto, si los principios en sentido preeminente son principios del 
movimiento, los matemáticos no serán principios en sentido preeminente y propio, sino sólo por semejanza (1222 b 23-28);

- el hombre es principio de un cierto movimiento en cuanto es principio de las acciones y la acción es movimiento (1222 b 28-29);

- dado que el principio es causa de las cosas que de él derivan, si éstas son necesarias (si no pueden ser de otro modo), también serán necesarios sus principios, y si, por el contrario, aquéllas pueden ser del modo contrario del que son, también éstos serán de esa misma naturaleza (1222 b 2942);

- la primera consecuencia de un principio es una cosa necesaria, pero las consecuencias sucesivas pueden ser también cosas contrarias. De esta clase son las acciones de los hombres (de los mismos hombres pueden derivar acciones contrarias) (1223 a 1-4);

- todas las cosas de las que el hombre es principio pueden acaecer o no. Por consiguiente, el hombre es su causa (1223 a 4-9);

- la virtud y el vicio, siendo objetos del elogio y el vituperio respectivamente, pertenecen a la categoría de cosas que pueden ser o no ser. Por consiguiente, el hombre es su causa y principio (1223 a 9-15);

- tales son las cosas que se realizan en virtud de una elección deliberada (1223 a 15-20).

\subsection{La fundamentación ontológica}

Se ha apuntado ya a la estructura de marcado carácter consecuencial de esta sucesión de tesis, y la lectura de las mismas confirma la observación. Pero, por otra parte, y también en relación a la estructura de la argumentación aquí desarrollada por Aristóteles, es necesario atender a la fundamentación ontológica que da a la cuestión que pretende probar, a saber, que el hombre es causa y principio de sus acciones. Para probar esta tesis, Aristóteles parte de las nociones metafísicas de cau-

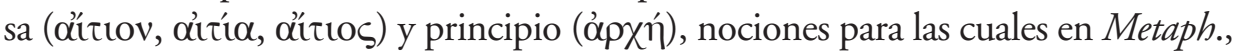
V, 1, 1013 a 18-19 se afirma que la característica básica del principio, subyacente a todos los significados que asume el término, es ser «el primer factor del cual <la 
cosa> o es o llega a ser», y en Metaph., V, 2, 1013 a 24 - b 8, después de aclarar que son causa (1) la materia, ya sea la materia próxima ya sea la materia remota de una cosa, (2) la forma o la esencia, así como sus partes y géneros remotos, (3) el primer principio del cambio, o sea, la causa eficiente y (4) aquello en vista de lo cual, es decir, la causa final, se precisa que de una misma cosa puede haber más de una causa, si bien no más de una causa del mismo tipo.

Ahora bien, precisamente sobre el principio como primer término del movimiento insiste la tesis (c), y la pluralidad de los significados de "causa» muestra el trasfondo de la instancia según la cual el hombre es causa de sus acciones: es cierto que se hace referencia a la acción como un tipo de movimiento y, por consiguiente, al hombre como causa del movimiento; no hay duda de que se le atribuye la causalidad eficiente de sus actos, pero — con toda evidencia - no sólo ésta, sino que, por otra parte, también la causa formal, final y material intervienen como causas del movimiento, en general, y de aquel movimiento particular que es la acción. En la argumentación, además, Aristóteles alude a la tesis metafísica según la cual las causas de las realidades inmóviles son ellas mismas inmóviles, allí donde las causas de las realidades contingentes, esas que pueden ser de un modo distinto del que son, son también de este mismo género. Alude asimismo a la distinción entre los principios de la matemática y aquéllos de las realidades en movimiento y, por lo tanto, en última instancia, al distinto estatuto ontológico de las entidades matemáticas y físicas, que es el tema de Metaph., VI, 1. Aún más: la tesis según la cual la sustancia en principio es de carácter metafísico, ya sea porque la sustancia, como es sabido, constituye el «significado focal» del ente en su multivocidad, ya sea porque en su significado de esencia, que es su significado primero (cfr. Metaph., VII, 3), aquélla coincide con la causa formal, de la que hemos señalado ya su valencia metafísica.

Pero todo esto, si bien por una parte certifica la posterioridad del conjunto de la Ética eudemia respecto de los libros de la Metafisica donde se exponen las doctrinas que acabamos de traer a colación y, en particular, la posterioridad respecto de aquellos libros VI y VII que según el parecer prácticamente unánime de la crítica contienen teorías formuladas por Aristóteles en un momento relativamente tardío de su actividad investigadora, por otra parte evidencia el nivel de plena madurez doctrinal y metodológica que ostenta el Estagirita en la composición de este tratado, donde la fundamentación de una tesis ética (el hombre es principio y causa de sus acciones) hunde sus raíces en los análisis metafísicos de las nociones en 
ella utilizadas (precisamente las de causa, principio y sustancia) sin que por ello se transgreda el principio según el cual cada ciencia debe hacer uso de principios válidos para el género de realidad que estudia, o, dicho de otro modo, sin usurpar los

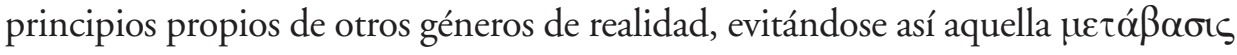

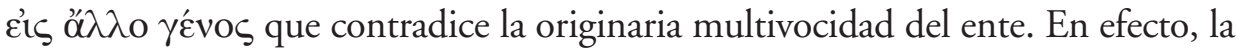
referencia a la valencia metafísica de las nociones puestas en juego en la argumentación que aquí examinamos no implica el que se esté haciendo uso en la misma de principios de una ciencia - la ontología - en el ámbito de una investigación de naturaleza moral, pues una cosa es un principio ontológico, es decir, un principio que tiene valor en el campo de la ontología y sustenta tesis de este tenor, y otra cosa distinta es mostrar cómo el principio de una determinada ciencia — en el caso que nos ocupa, un principio ético—-, siendo examinado en relación a esa ciencia y ostentando solamente un valor en el ámbito de la misma, requiere asimismo de nociones de naturaleza metafísica. Tal cosa no complica de ningún modo la aplicación del principio más allá de los límites epistémicos a los cuales está constitutivamente vinculado, es decir, en relación a géneros de realidad ulteriores a aquéllos de los que es principio, sino que vale como justificación de aquél proporcionada a un nivel general, al que podemos referirnos, con terminología moderna, como metateórico; $y$, exactamente, a un nivel general se coloca la ontología, por ser ella misma ciencia del ente en cuanto ente, es decir, del ente en su totalidad. Ahora bien, los principios que intervienen en la argumentación examinada son de naturaleza exclusivamente ética, ya que sólo funcionan en esta precisa valencia y para este ámbito de la realidad, a pesar de que a nivel metateórico requieran que se pongan en juego nociones de orden ontológico-metafísico y depositen en ellas, en última instancia, su espesor especulativo.

Así pues, el uso en la investigación de la Ética eudemia de tal orden de nociones sin alterar mínimamente el estatus epistemológico de la ciencia ética evidencia precisamente, además de la madurez doctrinal de Aristóteles ya observada, la adquisición de una plena madurez metodológica.

Todo esto, junto a los apuntes precedentes en relación a la fuerte cohesión lógica de las tesis que intervienen en la argumentación y al conocimiento alcanzado de las doctrinas ontológicas propias de la filosofía aristotélica, permite decir que la composición de la Ética eudemia debe ser colocada en un momento relativamente tardío de la trayectoria especulativa de Aristóteles. Un momento que, si tenemos en cuenta que un tal examen a propósito del hombre como principio y causa de 
sus acciones, con la importancia que el mismo tiene para la arquitectura de la teoría moral también común a la Ética nicomáquea, no se encuentra en este tratado, se revela necesariamente como posterior al momento de composición de ésta.

\section{La voluntariedad y la involuntariedad en la Ética eudemia y en la Ética nicomáquea}

El análisis de la voluntariedad y la involuntariedad constituye, por otra parte, el capítulo en el que podemos apreciar una mayor diferencia entre la Ética eudemia y la Ética nicomáquea. Esta diferencia se hace evidente a partir del hecho de que en el examen del primer tratado se desarrollan una serie de anotaciones temáticas y se prosigue según desarrollos que permiten clarificar, según varios puntos y distintos aspectos, la propia autonomía respecto al tratamiento del otro tratado, en el que no hay rastro ni de las primeras ni del segundo.

Desde este punto de vista se hará necesario averiguar si estas «novedades» representan una maduración conceptual y metodológica respecto a los temas y a la lógica según los cuales se articulan los análisis correspondientes de la Ética nicomáquea. En particular, se hace necesario averiguar si la investigación de la Ética eudemia propone la misma doctrina de la Ética nicomáquea, aunque disponiéndola de modo distinto, o si, por el contrario, subsiste también una diferencia doctrinal entre estas obras; $y$, en el primer caso, en qué términos se delinea la «novedad» doctrinal de la Ética eudemia: como una suerte de concentración o síntesis de los argumentos efectivamente presentes en la Ética nicomáquea o cuando menos implícitos en las tesis que en ella se desarrollan, y según una lógica argumentativa más adecuada para hacer comprender tales tesis; o como una elaboración de conceptos y recorridos que tienen poco o nada que ver con los de la Ética nicomáquea.

En cualquiera de las dos hipótesis, no obstante, será posible verificar el grado de madurez alcanzado en los dos tratados según los parámetros de la precisión conceptual y del rigor lógico. Y está claro que, según el orden de las consideraciones y el planteamiento del discurso, si la investigación de la Ética endemia se presentara como no menos precisa que la Ética nicomáquea en las definiciones de los contenidos conceptuales y no menos rigurosa en la articulación de sus recorridos, habrá que concluir que, respecto a ésta, aquélla es posterior. 


\section{Un plano común}

Aun así, las diferencias de método y de contenido a las que nos hemos referido no deben impedir que se observe cómo las dos investigaciones incluyen en un plano común sus disquisiciones sobre la voluntariedad, donde se busca definir la elección deliberada ( $\pi \rho \alpha^{\prime}(\rho \varepsilon \sigma \iota \varsigma)$ y la relación de ésta con las virtudes éticas. Así pues, desde este punto de vista el diseño general es el mismo y deja ver un proyecto de investigación idéntico, el cual, a su vez, revela una misma concepción de fondo. Se ha afirmado ya, y ahora insistimos en ello, que la elección deliberada es algo voluntario, de modo que la aclaración sobre lo que sea lo voluntario es útil para la aclaración conceptual de la elección deliberada; y dado que es imposible que las virtudes no se expresen en actos deliberadamente elegidos, se hace necesario indagar la relación entre la elección deliberada y las virtudes éticas.

Ahora bien, este diseño está claro en la Ética nicomáquea, y se puede constatar comenzando por la sucesión de los capítulos que integran tal investigación: con el objetivo de definir qué es lo voluntario, Aristóteles comienza por determinar qué es lo involuntario, y en Eth. nic., III, 1 establece que es sobre todo involuntario lo que es forzoso, precisando que son forzosas las acciones cuyos principios son extrínsecos al sujeto y en los que el sujeto mismo no ha participado en absoluto. A continuación, en Eth. nic., III, 2, indica la segunda condición de la involuntariedad de una acción: la ignorancia de las circunstancias particulares en las que ella se desarrolla, identificadas en el agente, en la acción misma, en el objeto, en el dominio de la acción, en el medio, en el resultado y en el modo. Además, el estagirita aclara que para que sea involuntaria la acción realizada por ignorancia, es decir, la acción de la cual es causa la ignorancia, se requiere que el sujeto sienta dolor o repugnancia, debiendo considerarse tal acción, en caso contrario, como "no voluntaria». Apunta, por otra parte, que el actuar por ignorancia, es decir, ignorando las condiciones particulares bajo las que se desarrolla la acción, es distinto del actuar ignorando la regla general de conducta, es decir, lo que se debe o no se debe hacer: pues ignorar esto no implica la involuntariedad de la acción (que en este caso no es causada por la ignorancia sino por otro factor, como por ejemplo por la embriaguez o la ira, cuando se hiera o mate a alguien en un tal estado o por una tal pasión, que hacen ignorar la regla según la cual no se debe 
matar), sino sólo su carácter malvado. Así definido lo involuntario, en Eth. nic., III, 3 precisa que la acción voluntaria es, por lo tanto, aquella acción que tiene su principio en el sujeto, quien no ignora las condiciones particulares bajo las cuales se desarrolla la acción. En este sentido, el estagirita demuestra que las acciones realizadas por apetito ( $\dot{\varepsilon} \pi \imath v \mu \mathfrak{i} \alpha)$ o por impulsividad $(\theta v \mu o ́ \varsigma)$ son voluntarias ${ }^{1}$. Así, establecido esto, en Eth. nic., III, 4 Aristóteles define la naturaleza y el objeto de aquella acción voluntaria que es la elección delibe-

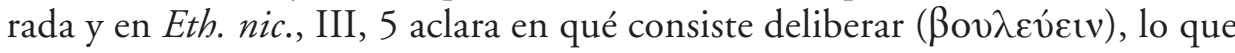
interviene para definir la elección deliberada como aquello que la diferencia específicamente en el interior del género de lo voluntario.

En la Ética eudemia el proyecto es fundamentalmente el mismo: en primer lugar se procede al análisis de la involuntariedad (caps. 7 y 8), a continuación se analiza la voluntariedad (cap. 9), después se determina lo que sea la elección deliberada (cap. 10), y finalmente se estudia la relación entre virtud ética y elección deliberada (cap. 11). Ahora bien, a pesar de que la concentración de los argumentos en una extensión menor y el distinto modo de ordenar la materia, rasgo al que hemos hecho referencia anteriormente (y sobre el que nos detendremos más atentamente a continuación), hace que, en general, el tratamiento de estas cuestiones sea menos claro y lineal en su fisionomía total, la cual, por ello mismo, puede resultar menos visible, basta con que se explicite el esqueleto de la exposición, prescindiendo de los detalles que la cubren, para constatar que se trata de la misma estructura que encontrábamos en la Ética nicomáquea.

\footnotetext{
${ }^{1}$ Los argumentos serían los siguientes: (1) el comportamiento de los animales y los niños es irracional, pero no por ello deja de ser espontáneo (1111 a 25-26). (2) Sería absurdo que las acciones moralmente bellas realizadas por apetito e impulsividad fuesen involuntarias y que aquellas moralmente malas debidas a los mismos factores fuesen voluntarias. De hecho no es posible realizar acciones moralmente bellas a causa del apetito o la impulsividad, ya que éstas son, ambas, formas irracionales del deseo (1111 a 27-29). (3) Tenemos el deber moral de desear ciertas cosas (y de irritarnos con otras), y el deber moral comporta voluntariedad (1111 a 29-31). (4) Las acciones involuntarias comportan dolor, mientras que las acciones llevadas a cabo a causa del apetito y por impulsividad proporcionan placer (1111 a 32-33). (5) Las acciones cometidas por apetito y por impulsividad, como aquéllas realizadas según un cálculo, son también propias del hombre. Por lo tanto, no puede pensarse que las primeras sean involuntarias y las segundas voluntarias (1111 a 33-b 2).
} 
De este modo toma forma la hipótesis según la cual la necesidad de compendiar en un mismo diseño general una materia analítica y ampliamente tratada con anterioridad habría inducido al Estagirita a disponer la materia misma de un modo diferente respecto a la más amplia presentación anterior, recurriendo asimismo a análisis y argumentos «nuevos», pues éstos sintetizarían razonamientos extensamente desarrollados en la Ética nicomáquea, y dejando además inexplicados, pues quedan sólo sugeridos o aludidos, ciertos momentos sobre los cuales, en el seno de una exposición sintética y sumaria y en una presentación esencial de la doctrina, se puede y se debe creer razonablemente que es inadecuado extenderse en mayor medida.

\subsection{Una primera y sustancial diferencia}

Una primera y sustancial diferencia se detecta inmediatamente al comienzo del análisis de la Ética eudemia, y concierne al modo en el que en ella se afronta el tema de la voluntariedad.

Como se ha señalado supra, en la Ética nicomáquea Aristóteles comienza a tratar de la voluntariedad determinando cuándo una acción es involuntaria e, inmediatamente después de haber constatado la primera condición de la involuntariedad, es decir, la fuerza ( $\beta \dot{t} \alpha$ ), en el mismo capítulo (Eth. nic., III, 1) se dedica al problema $<\mathrm{I}>$ de las acciones llevadas a cabo para evitar males mayores o para conseguir mayores bienes (1110 a 4 - b 9); <II > después al de aquellas

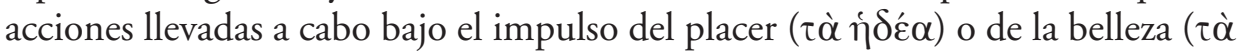
$\kappa \alpha \lambda \alpha$ ) (1110 b 9-16). Ambas clases de acción, de hecho, podrían parecer involuntarias, pudiéndose entender, en cierto sentido, que también ellas son llevadas a cabo por algún tipo de fuerza, una vez se considera que sus principios pueden creerse como externos al sujeto. Pero Aristóteles muestra que esto no es así y que, por el contrario, aquéllas son igualmente acciones voluntarias o, al menos, prevalentemente voluntarias.

$<\mathrm{I}>$ En cuanto a las primeras, de hecho, Aristóteles hace ver que poseen un carácter mixto de voluntariedad e involuntariedad, pero se parecen sobre todo a

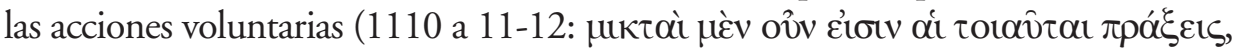

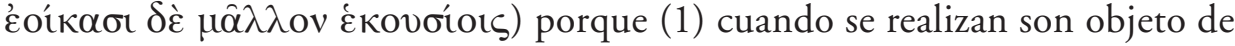
elección: son, efectivamente, escogidas como medios para conseguir los fines 
anteriormente mencionados (1110 a 13-15); (2) el principio del movimiento de las partes del cuerpo mediante las cuales tales acciones se llevan a cabo está en el sujeto (1110 a 15-19); (3) a veces por estas acciones se nos elogia, otras veces se nos vitupera, y tanto el vituperio como el elogio presuponen la voluntariedad (1110 a 19-23). El Estagirita apunta, no obstante, que si bien a veces el hombre no es elogiado, es, con todo, perdonado, como sucede cuando uno hace lo que no debe por causas que sobrepasan la naturaleza humana; pero éstos son casos raros, siendo necesario ser muy precavidos y no generalizar (1110 a 23-b 1).

$<$ II > También las segundas son acciones voluntarias porque (1) el placer y la belleza moral motivan todos los actos de los hombres, y sería absurdo decir que todas las acciones son involuntarias (1110 b 9-11); (2) quien actúa atraído por la belleza o por el placer, actúa con alegría, mientras que el sentimiento característico que acompaña a las acciones llevadas a cabo por la fuerza es el dolor (1110 b 11-13); (3) es ridículo considerar lo placentero de las cosas vergonzosas como causa de su ser llevadas a cabo y, por el contrario, considerarnos a nosotros mismos los principios de las acciones moralmente bellas (1110 b 13-14).

Así pues, en la Ética eudemia Aristóteles procede a determinar lo que sea lo voluntario y lo involuntario en relación a tres opiniones: una que localiza lo

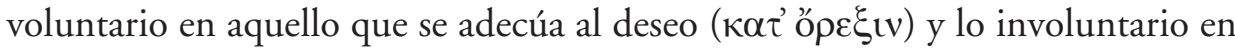
aquello que es contrario al deseo, otra opinión según la cual lo voluntario es aque-

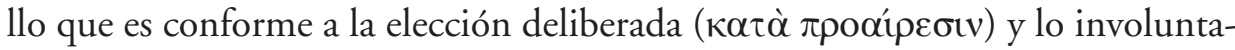
rio aquello que se opone a ésta, y una tercera opinión que hace residir lo volun-

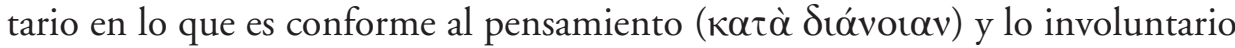
en lo que es contrario al pensamiento; procede a continuación a mostrar que lo voluntario no es aquello que está de acuerdo con el deseo (Eth. eud., II, 7) ni con la elección deliberada (Eth. eud., II, 7), ni lo involuntario con aquello que es contrario al uno y a la otra, para indicar, precisando y afinando la tercera opinión, que aquello que es voluntario es conforme a un cierto pensamiento y a un cierto conocimiento, exactamente a ese pensamiento y a ese conocimiento que tienen como objeto las determinaciones concretas de la acción: quién actúa, qué se lleva a cabo, el medio con el cual se lleva a cabo la cosa, mientras que quien actúa ignorando estas condiciones actúa involuntariamente. 
Se trata de la misma doctrina de lo voluntario y lo involuntario que Aristóteles elabora en la Ética nicomáquea en relación a la segunda condición de estas nociones, si bien — como está claro ya a partir de estos términos - en la Ética eudemia esa doctrina se alcanza a través de un recorrido marcadamente dialéctico, en cuanto se especifica concretamente en el examen peirástico y exetástico de un phainómenon. En este sentido, el desarrollo de la Ética eudemia es plenamente coherente y satisface precisamente la prescripción metodológica de Eth. nic., VII, 1 (1145 b 2-7) = Eth. eud., VI, 1, según la cual en las cues-

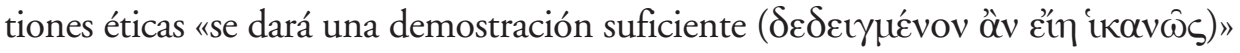
si, "después de establecer los hechos observados ( $\tau \imath \theta \dot{\varepsilon} v \tau \alpha \varsigma \tau \alpha \grave{\alpha} \phi \alpha \imath v o ́ \mu \varepsilon v \alpha)$ »

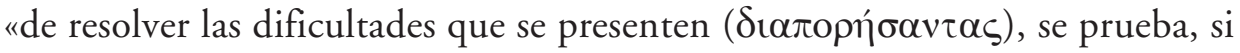
es posible, la verdad de las opiniones admitidas sobre estas pasiones». Ahora bien, en virtud de la plena conformidad para con este dictado metodológico, el desarrollo de la Ética eudemia demuestra haber alcanzado un grado de madurez doctrinal que exige colocar su composición en una fecha tardía de la actividad científica del Estagirita.

Sea como fuere, en este momento se hace necesario parar mientes sobre el hecho de que Aristóteles comienza sus análisis sin hacer referencia a la que en la Ética nicomáquea era considerada como la primera determinación formal de este tipo de acciones, la cual será tratada en la Ética eudemia sólo en el capítulo siguiente (II, 8); nos referimos a aquélla según la cual es una acción involuntaria la acción llevada a cabo por la fuerza. Deja de indicar la misma como si se tratara de una condición obvia por ya conocida, y entra inmediatamente a examinar dos tipos de acción cuya voluntariedad o involuntariedad se determina, en los mismos argumentos proporcionados por el Estagirita, en relación al ser o no ser forzados a actuar. Éste es, precisamente, el presupuesto, es decir, el trasfondo teórico sobre el cual emergen los análisis a propósito de las acciones llevadas a cabo bajo el

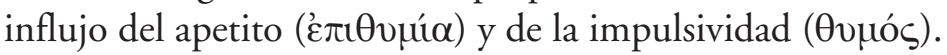

Trayendo a colación, como se ha señalado anteriormente, la opinión común

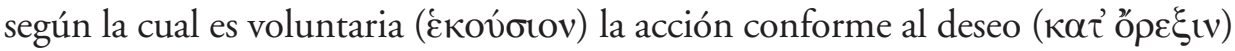

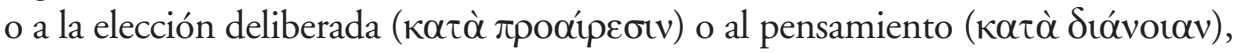

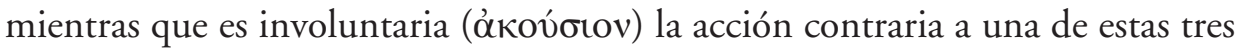

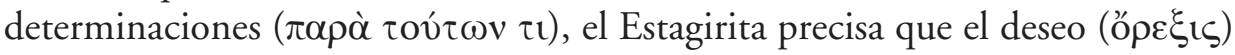
se distingue en la voluntad ( $\beta$ ov́ $\lambda \eta \sigma \iota \varsigma)$, que es deseo racional, en la impulsividad $(\theta v \mu o ́ \varsigma)$ y en el apetito ('غ $\pi \imath v \mu u ́ \alpha)$, siendo estas dos últimas deseos irra- 
cionales, y procede a demostrar en primer lugar que las acciones llevadas a cabo por apetito pueden ser consideradas tanto voluntarias como involuntarias (1223 a 29 - b 17); a continuación, que la misma situación se da en relación a las acciones llevadas a cabo por impulsividad (1223 b 18-28), con la consecuencia de que lo voluntario y lo involuntario, asumidos específicamente, no pueden identificarse con ninguno de los dos tipos de acciones consideradas, desde el momento en que ambas son tanto voluntarias como involuntarias; finalmente, prueba que

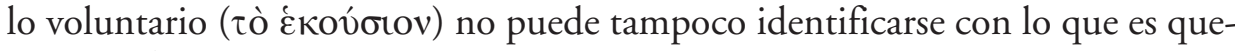

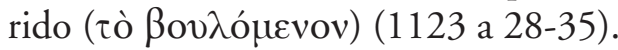

Así pues, en la Ética eudemia Aristóteles empieza a tratar de la voluntariedad y la involuntariedad examinando dos tipos de acciones para las cuales, y en orden a decidir si son voluntarias o involuntarias, es necesario presuponer aquella primera condición de estas determinaciones, es decir, la fuerza o la ausencia de fuerza, que siendo explícitamente indicada y ampliamente desarrollada en la Ética nicomáquea, en la Ética eudemia no es objeto ni de una elaboración expresa ni tampoco de referencia específica alguna, sino que se obvia como algo ya adquirido y conocido. Y que se deba considerar como algo ya adquirido lo prueba el hecho de que - como está claro a partir de los argumentos al respecto- sólo a partir del presupuesto especificado a partir de aquélla tiene sentido suscitar el problema de si las acciones llevadas a cabo por apetito o por impulsividad son en cierto modo acciones que implican en su principio fuerza y, por lo tanto, involuntarias, o no satisfacen en absoluto tal característica, sino que son plenamente voluntarias.

Más aún, muchos de los análisis que Aristóteles usa en la Ética eudemia para realizar el examen diaporemático a propósito de la voluntariedad y la involuntariedad de las acciones llevadas a cabo por apetito o por impulsividad son muy similares, y algunos incluso idénticos, ya en relación a aquéllos con los que en la segunda parte de Eth. nic., III, 3, después de haber definido lo que sea lo volun-

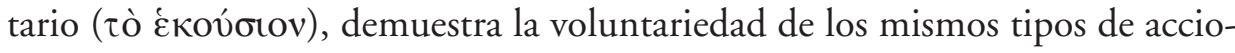
nes $^{2}$, ya en relación a aquéllos con los que en Eth. nic., III, 1, individuada la fuerza como la primera condición adecuada para considerar una acción como involuntaria, demuestra que las acciones llevadas a cabo para evitar males mayo-

\footnotetext{
${ }^{2}$ A este respecto cfr. supra, nota n. 1.

${ }^{3}$ A este respecto cfr. supra.
} 
res o para conseguir mayores bienes y las acciones inducidas por el placer o la belleza moral son voluntarias ${ }^{3}$.

Frente a las dos consideraciones hasta aquí realizadas, la hipótesis según la cual la investigación de la Ética eudemia es posterior a la de la Ética nicomáquea, de modo que la primera retoma, sintetiza y procede en su propio examen sobre el trasfondo de la determinación formal de la involuntariedad por la fuerza definida en la segunda, hipótesis que ya anteriormente se mostraba dotada de gran plausibilidad, se refuerza y confirma ulteriormente, dada también la constatación a propósito de la semejanza e incluso identidad de los argumentos con los que en ambas obras se refuta la presunta involuntariedad de acciones aun de tipo diferente.

\subsection{Las acciones Ilevadas a cabo por apetito o por impulsividad}

Aún más, para apoyar definitivamente esta hipótesis se añade el hecho de que los argumentos que el Estagirita, en un contexto específicamente diaporématico, aduce en la Ética eudemia a favor de la voluntariedad o la involuntariedad de las acciones llevadas a cabo por apetito o por impulsividad presentan una articulación fundamental tan rigurosa y esencial que permite incluso que se declinen en forma silogística, lo que es indicio de una inequívoca madurez de pensamiento y de un dominio de la materia que permite situar el texto en un momento posterior a aquél en el que las formulaciones de las pruebas no satisfacen esta característica, lo que sucede, precisamente, con la Ética nicomáquea.

En efecto,

$<1>$ El primer argumento que intenta probar la voluntariedad de las acciones llevadas a cabo por apetito o, precisamente, que aquello que es conforme al

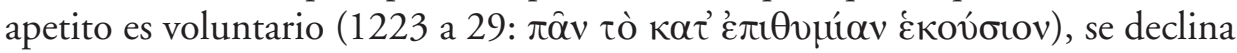
en el siguiente polisilogismo:

${ }^{4}$ Más sintéticamente, la voluntariedad de lo que es conforme al apetito, en el mismo contexto de la argumentación aristotélica, puede probarse también prescindiendo de la referencia a lo doloroso y declinarse así: lo que es realizado por la fuerza es involuntario; pero lo que es contrario al apetito es algo realizado por la fuerza; por lo tanto, lo que es contrario al apetito es involuntario. Se sigue que lo que es conforme al apetito es involuntario. 
Primer silogismo: lo que es forzoso es doloroso; lo que es contrario al apetito es algo que es forzoso; por lo tanto, lo que es contrario al apetito es doloroso.

Segundo silogismo: lo que es doloroso es involuntario; lo que es contrario al apetito es doloroso; por lo tanto, lo que es contrario al apetito es involuntario ${ }^{4}$.

Ahora bien, si lo contrario al apetito es lo involuntario, lo que es conforme al apetito es voluntario.

$<2>$ El segundo argumento se desarrolla en el siguiente polisilogismo:

Primer silogismo: la perversidad hace ser injustos; actuar por apetito es una perversidad; por lo tanto, actuar por apetito nos hace injustos.

Segundo silogismo: actuar por apetito contrariamente al cálculo es injusto; el intemperante actúa por apetito contra el cálculo; por lo tanto, el intemperante es injusto.

Tercer silogismo: lo que es injusto se lleva a cabo voluntariamente; el intemperante es injusto; por lo tanto, el intemperante actúa voluntariamente.

Cuarto silogismo: el intemperante actúa voluntariamente; actuar por apetito es actuar como un intemperante; por lo tanto, actuar por apetito es actuar voluntariamente.

$<3>$ El primer argumento con el que Aristóteles prueba la involuntariedad de las acciones llevadas a cabo por apetito tiene la siguiente estructura: actuar voluntariamente es llevar a cabo lo que se quiere. El Estagirita reconoce que rige también la recíproca, es decir, que la afirmación admite una conversio simplex, por la cual llevar a cabo lo que se quiere es actuar voluntariamente. La proposición funge de premisa mayor de un silogismo cuya premisa menor afirma «el intemperante no lleva a cabo lo que quiere», es decir, "el intemperante lleva a cabo lo que no quiere»; y cuya conclusión sería «por lo tanto, el intemperante actúa involuntariamente».

$<4>\mathrm{El}$ segundo argumento que induce a juzgar como involuntarias las acciones llevadas a cabo por apetito se articula en el siguiente polisilogismo: 
Primer silogismo: la virtud nos hace justos; la temperancia es una virtud; por lo tanto la temperancia nos hace justos.

Segundo silogismo: actuar justamente es voluntario; la temperancia nos hace justos, es decir, nos hace actuar justamente; por lo tanto la temperancia es voluntaria.

Tercer silogismo: La temperancia es voluntaria; pero actuar contra el apetito es actuar con temperancia; por lo tanto actuar contra el apetito es actuar voluntariamente.

Esta conclusión es la opuesta a la del argumento $<2>$ y, en particular, puede convertirse en aquélla según la cual el actuar por apetito es involuntario.

El argumento con el que Aristóteles prueba que las acciones cumplidas por impulsividad son voluntarias - más concretamente, que aquello que es conforme a la impulsividad es voluntario-, se declina según el siguiente polisilogismo:

Primer silogismo: lo que es doloroso es forzoso; lo que es contrario a la impulsividad es doloroso; por lo tanto lo que es contrario a la impulsividad es forzoso.

Segundo silogismo: lo que es forzoso es involuntario; lo que es contrario a la impulsividad es forzoso; por lo tanto lo que es contrario a la impulsividad es involuntario.

De donde se sigue que lo que es conforme a la impulsividad es voluntario.

\subsection{El caso del intemperante}

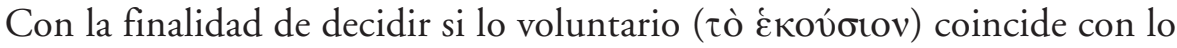

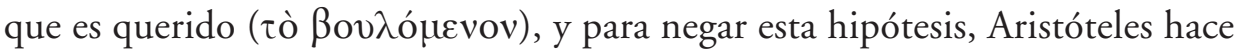
mención explícita al caso del intemperante, anticipando la noción de este hombre que será más tarde profundizada y esclarecida en el libro sexto, es decir, en el tercero de los llamados «libros comunes». Ya en el examen a propósito de la impulsividad, subrayando que la misma da lugar a una forma de intemperancia, 
de la que la otra forma sería el apetito (1223 b 19), se refleja el conocimiento de una doctrina que es objeto de análisis en el mencionado libro común, lo que representa un indicio elocuente de que los libros comunes preceden, en cuanto a la doctrina y a la composición, al tratamiento del mismo en la Ética eudemia.

La cuestión da pábulo a consideraciones que podrían desarrollarse en múltiples direcciones. Pero en este momento nos interesa subrayar el hecho de que para rechazar la identidad de las dos determinaciones arriba mencionadas Aristóteles desarrolla una argumentación aporética que se desglosa en dos silogismos con conclusiones contradictorias. Ahora bien, es a este modo de desglosarse la argumentación a lo que se ha de atender, pues permite extender la observación a propósito de la madurez de Aristóteles en la Ética eudemia, confirmada incluso por el dominio a nivel formal de la investigación, también al análisis de la relación entre voluntariedad (

El primer silogismo reza: la perversidad nos hace más injustos; la intemperancia es una clase de perversidad; por lo tanto la intemperencia nos hace más injustos.

El segundo se desarrolla del siguiente modo: lo que es voluntario ( $\tau$ ò $\beta$ ov-

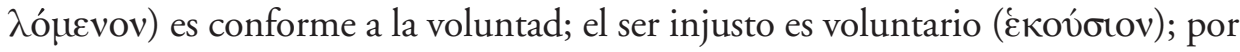
lo tanto ser injusto es conforme a la voluntad. Se desmiente así la conclusión del primer silogismo: pues, si el ser justo consiste en el actuar según la voluntad y el intemperante actúa contra su voluntad, entonces el intemperante no es injusto.

\section{Lo voluntario tampoco coincide con lo que es deliberadamente elegido}

En la primea parte de Eth. eud., II, 8 Aristóteles demuestra que lo volun-

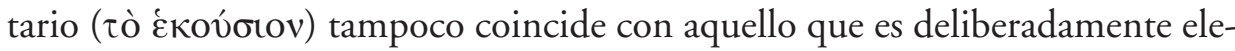

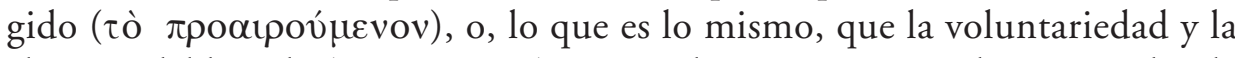
elección deliberada ( $\pi \rho o t \alpha i ́ p \varepsilon \sigma \iota \varsigma$ ) no son determinaciones idénticas, sobre la base de la observación de que también se actúa voluntariamente de modo espontáneo, pero no se elige deliberadamente de este mismo modo (1223 b 38 -1224 a 4$)$. 
También en este sentido la doctrina de la Ética eudemia es exactamente la misma que la de la Ética nicomáquea, pero es interesante la posición que tal disquisición ocupa en nuestro tratado. Sobre todo ha de señalarse que en la Ética nicomáquea el tema de la identidad o no de lo voluntario con lo deliberadamente elegido no se trata jamás, pero la no coincidencia de ambas determinaciones se sigue del examen de la elección deliberada, llevado a cabo en Eth. nic., III, 4, como aquella parte de lo voluntario que está precedida por una deliberación; de

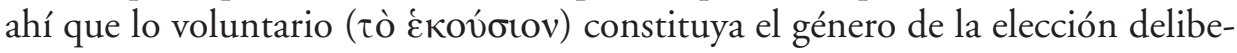
rada ( $\pi \rho o t \alpha i p \varepsilon \sigma \iota \varsigma)$, la cual tiene como su diferencia específica, precisamente, la

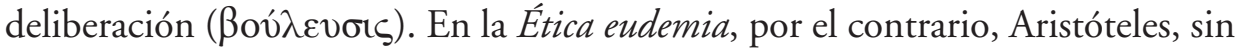
haber aún determinado formalmente la noción de elección deliberada —lo que realizará en II, 10- ya en II, 8 la presupone y sobre la base de la misma demuestra, como se ha dicho ya, la no coincidencia de lo que es deliberadamente elegido con lo voluntario. Pero, precisamente, el uso de la noción de elección deliberada antes de su definición formal e incluso anterior al tratamiento analítico de esta figura basilar de la doctrina ética, certifican que la misma no sólo era ya conocida, sino también definida según un grado de formalidad adecuado para utilizarla en una demostración. Y cuál sea el análisis de la elección deliberada al que Aristóteles se atiene, anterior a los desarrollos de la Ética eudemia —en la cual, a pesar de no haberle dedicado aún tiempo, usa la noción — no es difícil de especificar, debiendo entenderse que la referencia a este respecto es Eth. nic., III, 4.

\section{Lo voluntario consiste en obrar de acuerdo con alguna clase de pensamiento}

En Eth. eud., II, 8 y 9 Aristóteles, después de haber tratado «en negativo» de lo voluntario y de lo involuntario (Eth. eud., II, 7), es decir, después de haber precisado por qué estas nociones no pueden ser expresadas por dos de los tres phainómena enumerados a ese propósito, concluye desde el principio que aquéllas encontrarán su lugar en el ámbito del tercer phainómenon, de modo que «nos resta la alternativa de que lo voluntario consista en obrar de acuerdo con alguna clase de pensamiento» (Eth. eud., II, 8, 1224 a 7); a continuación, extraída esta conclusión, la cual, como puede verse fácilmente, introduce por vía dialéctica aquélla que en la Ética nicomáquea es la segunda condición de la voluntariedad, es decir, el conocimiento de las condiciones particulares en las que se desarrolla 
la acción, el Estagirita procede a examinar ampliamente aquélla que en la Ética nicomáquea es considerada como la primera condición de la involuntariedad, y a la cual — como hemos visto- se ha referido implícitamente, tomándola como noción ya conocida, al elaborar los argumentos destinados a excluir los dos primeros phainómena (II, 8); finalmente (II, 9) vuelve sobre el tercer phainómenon, lo precisa y aporta las precisiones pertinentes, para recabar, en base al mismo, según el oportuno tratamiento dialéctico, la conclusión de que la otra condición de la voluntariedad es justamente, como sucedía en la Ética nicomáquea, el conocimiento de los aspectos particulares de la acción. Ésta es, pues, al concluirse el expediente peirástico y exetástico, la especificación formal, configurada en doctrina, de aquello que era inicialmente indicado como obrar «de acuerdo con alguna clase de pensamiento (dianooumenon pos)»: el pensar en un cierto modo ahora se especifica como el pensar las susodichas determinaciones de la acción.

Al continuar la investigación sobre lo que es forzoso convendrá considerar sobre todo cómo Aristóteles la desarrolla en la Ética nicomáquea, en modo tal que seamos capaces de disponer de un terreno comparativo seguro para, una vez reconstruida la doctrina de la Ética eudemia, poder analizar la relación subsistente a este respecto en ambos escritos.

Ahora bien, en Eth. nic., III, 1, sobre lo que es forzoso Aristóteles se limita a decir, como hemos notado ya anteriormente, que (1) son forzosas aquellas acciones cuyo principio es exógeno al sujeto y (2) en las cuales el sujeto no participa de ningún modo 5 . La continuación de los análisis sobre esta cuestión está constituida por la demostración, mediante los argumentos indicados previamente, del carácter no forzoso, es decir, voluntario, de las acciones llevadas a cabo para evitar males mayores o para conseguir mayores bienes; así como de aquéllas realizadas a causa del placer o de la belleza moral. Segunda parte ésta que, por lo que hace a nuestro actual cometido, puede ser soslayada, ya que no comporta ninguna aportación a la determinación positiva del concepto de fuerza, al cual se alude según las dos características consignadas supra.

${ }^{5}$ Cfr. Eth. nic., III, 1, 1110 a 1-4: «es forzoso aquello cuyo principio es externo y de tal clase que en él no participa ni el agente ni el paciente; por ejemplo, si uno es llevado por el viento o por hombres que nos tienen en su poder». 
Así pues, frente a esta escueta caracterización, el análisis de la Ética eudemia se destaca inmediatamente por su amplitud y profundidad.

Dado que corresponde a un phainómenon (cfr. 1224 a 9: ठокعi), que «aque-

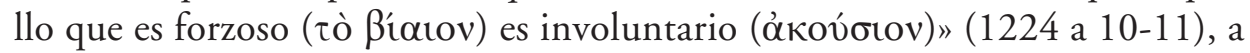
partir de esta noción común Aristóteles instituye explícitamente una investigación destinada a esclarecer (a) qué es lo que se debe entender que es por la fuerza ( $\tau$ ò $\left.\beta^{\prime} \alpha\right)$ y (b) cómo se relaciona esto con lo voluntario y lo involuntario (1224 a 11-13). Está claro que se trata de una indagación que aplica totalmente el método dialéctico en su función crítico-valorativa y que, siguiendo la indicación - ya señalada - de Eth. nic., VIII, 1 = Eth. eud., VI, 1, procede

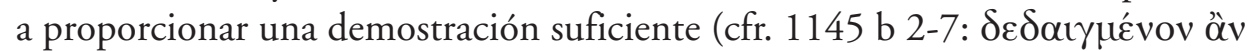

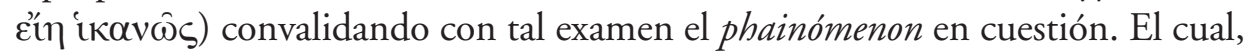
por ello mismo, asume la fisionomía de un éndoxon, es decir, de una opinión que, siendo suficientemente conocida, constituye un punto de apoyo de las demostraciones sucesivas y no exige a su vez ser sometida ella misma a ulteriores exámenes críticos.

Aristóteles completa el examen de lo que hay que entender como forzoso ( $\tau$ ò

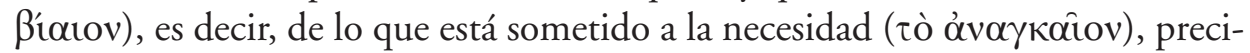
sando ante todo que ello, desde el común modo de pensar (cfr. 1224 a 15: ठокعi),

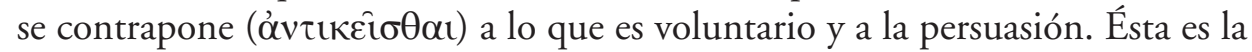
respuesta al punto (b) del preanunciado examen dialéctico. Una respuesta que también bascula en torno al fiel del modo común de pensar porque evidentemente no considera esta opinión un simple phainómenon, en relación al cual se necesita de un examen crítico-valorativo, sino un éndoxon.

Por el contrario, en lo que concierne al punto (a), Aristóteles aclara la noción de «forzoso ( distinguiendo dos usos lingüísticos del término. Precisa, por lo tanto, que se habla de lo forzoso también en el caso de las cosas inanimadas, y entonces el término asume el significado de contrario al lugar en el que la cosa se encuentra por naturaleza. Así, la piedra que por naturaleza tiende a ir hacia abajo y el fuego que por naturaleza tiende a ir hacia arriba, en el caso de que fuesen llevadas hacia arriba, la primera, y hacia abajo, el segundo, han sido sometidos a la fuerza y la necesidad (1224 a 15-18). 
Como es evidente, entra aquí en juego la doctrina de los lugares naturales de los cuerpos físicos, la cual interviene constitutivamente en la determinación

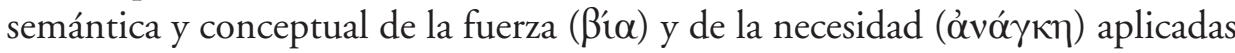
a este género de entidades. En efecto, ella constituye su presupuesto teórico.

Aun así, el filósofo precisa que en el caso de las entidades inanimadas, a pesar de que en el caso de que se muevan contra natura se hablará precisamente de fuerza, no se hablará de voluntariedad cuando se muevan según sus naturalezas (1124 a 18-20). Es una de las características de la relación voluntariedad-fuerza en este tipo de entidades respecto a aquellas vigentes para los seres animados, junto a otras que serán aclaradas en breve.

Es distinto, por el contrario, el significado que asumen los términos en relación a los seres animados y, en particular, al hombre. En este caso la fuerza (y la necesidad) designa una situación en la que algo exterior ( $(\xi \xi \omega \theta \dot{\varepsilon} v \tau \imath)$ a estas entidades las mueve contra el impulso que tienen en sí mismas ( $\pi \alpha \rho \grave{\alpha} \tau \eta \dot{v} v \dot{\varepsilon} v \alpha \nu ̉ \tau \omega \hat{~}$ ópuńv) (1224 a 20-23). Aun así, hay una diferencia fundamental entre la involuntariedad de los animales y la del hombre, diferencia que permite encontrar un punto de contacto entre los primeros y los seres inanimados, como subraya

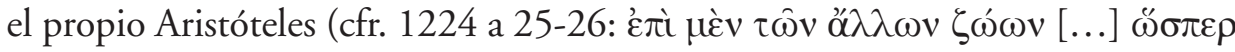

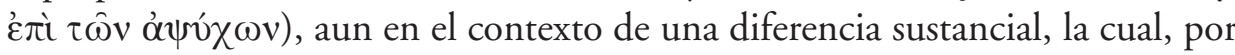
el contrario, es total y excluye cualquier punto de contacto entre el resto de los animales y el hombre. Y es que se da el hecho - precisa Aristóteles- de que el

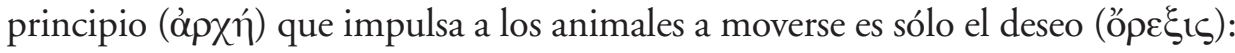
se trata, evidentemente, de un deseo irracional, ya que los animales no partici-

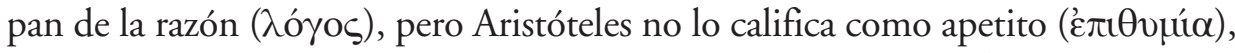

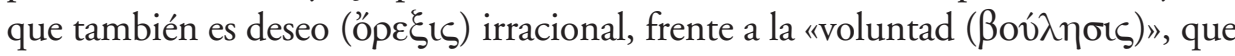
por el contrario es deseo (ős $\xi i \varsigma)$ racional, pues reserva la determinación de «ape-

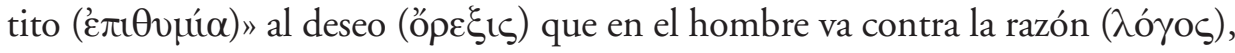
no al deseo de aquellos seres humanos que no participan ellos mismos de la razón, deseo que es naturaliter irracional, en el sentido de que no puede ser sino irracional, por cuanto es el único principio de su movimiento, y es un principio que, por decirlo así, no tiene que ajustar cuentas con el principio de la razón.

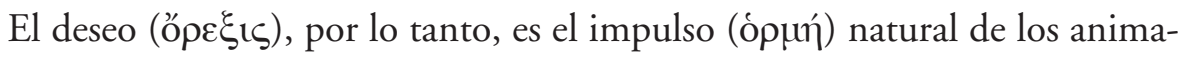

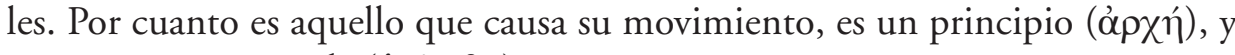
es un principio simple ( $\dot{\alpha} \pi \lambda \circ \hat{\jmath} \varsigma)$ porque es único. 
Aquí, como se señalaba, encontramos el punto de contacto y a la vez la diferencia entre el impulso (ópứ) según el cual se mueven los seres inanimados y aquél según el cual se mueven los animales: el punto de contacto reside en el hecho que

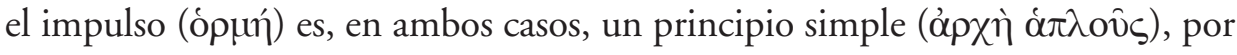
cuanto es el único y, no obstante, no debe — por decirlo así — rendir cuentas ante ningún otro; la diferencia se da por el hecho de que el impulso (ópứ) que mueve a los seres inanimados es una tendencia ligada a los lugares naturales, y por lo tanto totalmente extraña a la psique, mientras que aquél que mueve a los animales

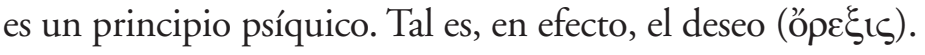

Lo que, por el contrario, mueve al hombre a actuar, es por una parte el deseo (ópe $\xi_{i} \varsigma_{\zeta}$ ), igual que en el caso de los otros seres vivos, es decir, en el caso de los animales, pero en este caso el deseo ha de rendir cuentas a la razón ( $\lambda$ óyos), y por lo tanto, entre estos dos principios puede verificarse un acuerdo, y entonces el deseo es voluntad ( $\beta$ ov́ $\lambda \eta \sigma \iota \varsigma)$, pero también puede resultar un conflicto entre el deseo y la razón. La diferencia frente al impulso que mueve a los seres inanimados es aquí total y no admite punto alguno de contacto: ya que en los seres inanimados el impulso de su movimiento es una tendencia natural, mientras en el hombre es el deseo (ópe $\xi_{1} \varsigma_{\text {) }}$, es decir, una facultad psíquica; en los seres inanimados es un principio simple, en el hombre no es simple, porque el deseo debe relacionarse con la razón.

Ahora bien, a partir de estas observaciones resulta que, si lo involuntario

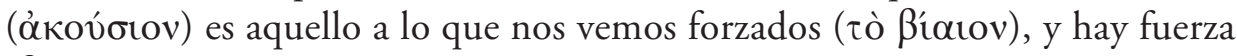
( $\left.\beta^{\prime} \alpha\right)$ «cuando algo externo [...] los mueve contrariamente a su propio impulso interno» (1224 a 22-23), dado que el impulso (ópứ) (a) en los seres inanimados es la tendencia a ir hacia el lugar natural, (b) en los animales es el deseo (ópe-

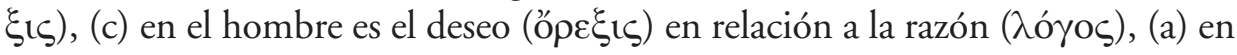
el caso de los seres inanimados se verifica involuntariedad (la noción de ókoúorov, como puede verse, es tan amplia como para extenderse también a tales entidades; por eso algunos intérpretes han afirmado que para Aristóteles las nociones

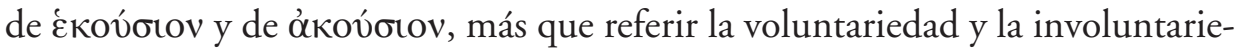
dad expresarían, propiamente, la espontaneidad o la ausencia de espontaneidad) cuando la cosa sea movida por algo exterior que la lleve en una dirección contraria a aquella que es su tendencia natural; (b) en el caso de los animales se verifica involuntariedad cuando algo exterior los haga actuar contra su deseo (őpe$\xi(\varsigma)$ : por ejemplo, cuando deseen ir en el sentido del alimento, pero se tire de 
ellos con una cuerda en el sentido opuesto (he aquí la semejanza con la involuntariedad de los seres inanimados: una piedra tiende a moverse hacia abajo, pero una cuerda la lleva hacia arriba; y simultáneamente su diferencia, pues en el caso de los animales el impulso frente al que se opone algo es un principio psíquico, mientras que en el caso de los seres inanimados se trata de un principio meramente físico); (c) en el caso del hombre (c/1) no hay duda de que hay invo-

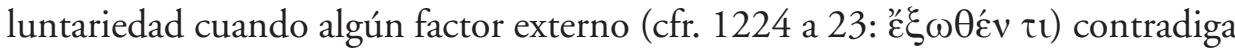
su deseo (óp $\xi_{1}(\varsigma)$ : por ejemplo, en el caso de que alguien deseara ir a Megara, pero unos ladrones lo retuvieran; (c/2) cuando por el contrario lo que contradiga el deseo (óp $\varepsilon_{\xi}(\varsigma)$ no sea algo externo, sino un principio interno al hombre mismo, y en especial la razón ( $\lambda$ ó $\gamma o \varsigma)$, ya que con ella, como se ha visto, se relaciona el deseo, se abre un problema consistente en que el darse de la involuntariedad no sólo no será inmediatamente claro, sino que, más bien, será del todo incierto: ya que, si por una parte aquélla parece darse desde el momento en que el deseo (óp $\xi_{1}(\varsigma)$ ), encuentra una resistencia, pues con ello encuentra una resistencia el impulso (ópứ) mismo que lleva a actuar, dado que el propio deseo (ő $\rho \xi \xi \varsigma)$ es lo que mueve, mientras la razón ( $\lambda$ ó $\gamma o \varsigma)$ no mueve nada, por otra parte la involuntariedad parecería no darse desde el momento en que se considere, en el caso que examinamos, que no se da la condición de la exterioridad ('̌́ $\xi \omega \theta \dot{\varepsilon} v \tau \iota)$ de aquello que opone resistencia al impulso. La razón, en efecto, no es algo externo, sino un principio interno del propio hombre: tan interno como para definir él mismo la diferencia específica que constituye su esencia en el interior del género de la animalidad. Éstos son exactamente los casos de la persona intemperante y de la persona temperante, en los que el contraste entre el deseo y la razón se concreta en la circunstancia de saber, el primero, lo que está bien llevar a cabo y sin embargo llevar a cabo, abocado por el placer, lo que está mal, y de sentir placer, el segundo, por ciertas acciones y, aun así, abstenerse de llevarlas a cabo porque sabe que está bien actuar así.

Mostrando que tanto las acciones del temperante como las del intemperante son voluntarias - tema que ocupa al Estagirita durante gran parte de los desarrollos de Eth. eud., II, 8-, Aristóteles resuelve el problema supra suscitado (c/2). En efecto, no sólo el intemperante, sino también el temperante está sometido a

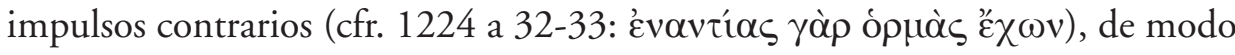
que tanto el uno como el otro, por el hecho de advertir ambos impulsos y de que ambos sean parte de ellos, si por un lado parecen actuar de acuerdo con ellos mismos y, por lo tanto, voluntariamente, por otro lado parecen actuar contradi- 
ciéndose a sí mismos y, por lo tanto, involuntariamente. De ahí el problema de la voluntariedad o la involuntariedad de sus comportamientos.

\subsection{La mayor precisión y la profundidad de análisis de la Ética eudemia}

En cualquier caso ha de tenerse presente que, si bien este problema se suscita en relación a ambos sujetos, es decir, no sólo para el intemperante, sino también para el temperante, Aristóteles considera que el problema es más serio y problemático en relación al primero, por lo que, aunque los análisis comprendan los comportamientos de ambos, la preocupación fundamental del Estagirita es estudiar el comportamiento del intemperante y mostrar su carácter voluntario. Un análisis de los argumentos con los que él prueba claramente la voluntariedad de las acciones de ambos sujetos muestra, de hecho, que tales argumentos están pensados en primer término en relación a la figura del intemperante.

Pero antes de proceder a examinar estos argumentos se hace necesario considerar la amplitud y profundidad de los análisis de la Ética eudemia sobre la primera condición de la involuntariedad de una acción, es decir, sobre la fuerza, frente a las consideraciones mucho más breves y superficiales ofrecidas en relación al mismo asunto en la Ética nicomáquea, donde, en particular, no se precisa en absoluto que la fuerza - y, por lo tanto, la involuntariedad - se extienda tanto a los seres animados como a los inanimados y, entre aquellos, al hombre;

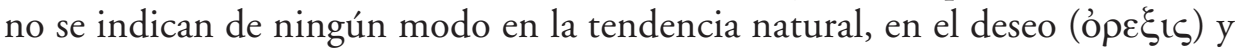
en la razón ( $\lambda$ oyos) los factores que intervienen para determinar la constricción $y$, para acabar, no se plantea el caso de la complejidad del impulso, cuando hay contraste entre deseo y razón, y el problema que con ello se abre en relación al carácter forzoso o no de la acción.

La mayor precisión y la profundidad de análisis de la Ética eudemia certifican la adquisición por parte de Aristóteles de un grado de madurez doctrinal inexistente en el desarrollo de la Ética nicomáquea, una madurez que -evidentemente- él ha adquirido repensando el mismo argumento después de un primer y más impreciso desarrollo. Puede decirse que éste, al presentar la noción de fuerza, retoma a todas luces la concepción corriente de la misma sin llevar a cabo en relación a ella ningún examen crítico y, por ello mismo, sin aportar ninguna acla- 
ración conceptual relevante y, con ello, consecuentemente, otras sofisticaciones doctrinales. Esa, de hecho, parece ser la situación de una tesis en la que se define lo forzoso como aquello de lo que no participa el sujeto porque su principio es externo. ¿En qué casos se verifica esta situación? ¿Cuáles son los factores contra los que un principio externo opone resistencia? ¿Y qué decir cuando la oposición no se establece entre un principio externo y uno interno sino entre dos principios internos? Estos son argumentos que en el tratamiento breve dedicado a la cuestión en la Ética nicomáquea no son siquiera rozados por Aristóteles. La diferencia con respecto a la Ética eudemia es evidente, y con ello, la mayor madurez doctrinal de este segundo texto.

\section{La voluntariedad tanto de la acción del temperante como de la del intemperante}

También la demostración a propósito de la voluntariedad tanto de la acción del temperante como de la del intemperante evidencia el claro dominio doctrinal del tema, pudiendo también verificarse ésta tanto en la profundidad de los contenidos, como en el rigor lógico de la relativa formulación, a partir del modo de plantear el problema. Aristóteles lo presenta, de hecho, bajo la forma de contraposición de tesis antitéticas, para el sostén de las cuales se aportan sólidos argumentos basados en instancias ya establecidas. El planteamiento dialéctico de tal desarrollo es evidente. Se ponen así como premisas tres éndoxa, según los cuales (a) «todo lo forzado ( $\beta$ '́a ov ) parece ser penoso», (b) «nadie que obra por la fuer-

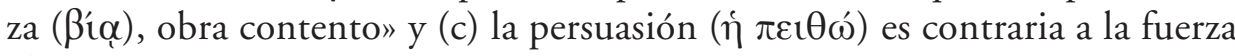
( $\left.\beta^{\prime} \alpha\right)$ y a la necesidad ( $\left.\alpha^{\prime} \alpha^{\prime} \gamma \kappa \eta\right)$, por lo que actuar porque se está persuadido es actuar voluntariamente. Sobre esta base, por una parte se representa la posibilidad de que la persona temperante actúe involuntariamente, ya que «se aparta por la violencia ( $\beta^{\prime}(\alpha)$ de los apetitos agradables» (1224 a 34-35) que advierte; mas actuar por violencia es lo mismo que actuar forzosamente ( $\beta$ íatos), y la fuerza es condición de la involuntariedad. Pero, por el contrario, esta misma persona «se dirige hacia lo que está persuadido", y por lo tanto "procede no por fuerza, sino voluntariamente» $(1224 \mathrm{a} 39-\mathrm{b} 1)$.

Del mismo modo también el intemperante parece actuar, por una parte, invo-

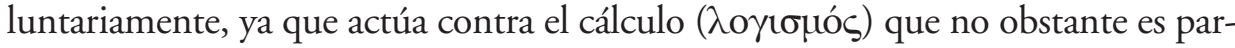
te de sí, y actuar contra la propia determinación es actuar involuntariamente 
(1224 a 36). Más aún, pues, actuando por apetito ( mismo contra la que es su propia convicción a propósito de cómo se debe actuar (1224 b 1-2), y actuar contra la propia convicción es involuntario. Por el contrario, su comportamiento es placentero, y el placer es indicio de voluntariedad.

La solución del problema es planteada por Aristóteles en base a cuatro argumentos.

El primero hace palanca sobre el hecho de que tanto el intemperante como el temperante son guiados en sus acciones por un principio que está en ellos mismos, mientras que la fuerza, tal y como ha sido definida, es causada por algo que proviene del exterior (1224 b 5-15). El núcleo del argumento reside en la consideración de que la contrariedad entre sí de los factores que determinan el impulso (ópứ) no niega que ambos factores sean internos al sujeto que actúa. El contraste tiene que ver, por decirlo así, con la estructura y la dinámica del impulso, no con su ser una fuerza motriz «del» sujeto y no ya de algo distinto de él. Dicho de otro modo: la interioridad del impulso al sujeto y su constitución, expresada en los casos aquí tratados en la oposición entre dos factores, son determinaciones que se encuentran en niveles distintos de consideración, de modo tal que ninguna de las dos interfiere en la otra.

El segundo argumento (1224 b 15-35) hace palanca, por el contrario, sobre el aspecto de totalidad del impulso considerado en su conjunto. Él está, ciertamente, constituido por factores contrastantes entre sí, pero así como en el primer argumento se mostraba que tal contraste no supone menoscabo alguno para la interioridad del impulso mismo, en este segundo argumento se muestra que tal contraste no supone menoscabo alguno para la unidad misma del impulso. La totalidad, en efecto, es la unidad de los componentes. Así, la presencia tanto en el intemperante como en el temperante de placer y dolor tiene como efecto que se necesite la parte desiderativa de su alma, por lo que sólo ésta se considera forzada, pero su alma en cuanto totalidad, considerada en cuanto conteniendo también el pensamiento (el cálculo), que, a la par del deseo, se encuentra tam-

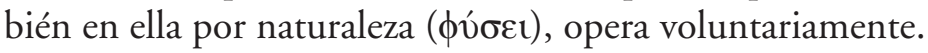

De particular interés es la especificación que Aristóteles ofrece del ser «por naturaraleza ( $\phi \dot{\sigma \varepsilon \imath) » . ~ e n ~ e s t e ~ c o n t e x t o ~ a r g u m e n t a t i v o . ~ E s ~ t a l ~ — e x p l i c a — ~ a q u e-~}$ 
llo que acompaña a todos los sujetos apenas vienen al mundo y si la generación se ha producido sin defecto alguno, y que hace proceder rectamente (1224 b 3134). Ésta es una sofisticación conceptual que contribuye a atestiguar la profundidad del análisis de la Ética eudemia y, por consiguiente, la madurez de pensamiento alcanzada en ella por Aristóteles.

En el tercer y en el cuarto argumento, Aristóteles retoma, en resumidas cuentas, el tema de las acciones llevadas a cabo para evitar males mayores y conseguir mayores bienes que en Eth. nic., III, 1 presenta, como hemos visto, como casos que no dejan ver inmediatamante si se fuerza o no al agente, y, por lo tanto, si hay o no involuntariedad. La solución que Aristóteles da en la Ética eudemia sintetiza y simultáneamente esencializa la que ofreciera ya en la Ética nicomáquea, sin perder nada en profundidad especulativa y en especificidad doctrinal. En la Ética nicomáquea sostiene que estas acciones tienen un carácter mixto de voluntariedad e involuntariedad, si bien deben considerarse fundamentalmente como voluntarias, algo que demuestra con tres pruebas ${ }^{6}$. En la Ética eudemia restringe la reflexión a su aspecto basilar y, después de haber aclarado cómo se puede pensar que se actúa por constricción en casos en los que no se da conflicto alguno entre pensamiento (razón, cálculo) y deseo, sino que se conoce que, si no se lleva a cabo una cierta cosa, habrá consecuencias dolorosas (golpes, cadenas, muerte, etc.), concluye que en tales casos no se da involuntariedad, poniendo en juego sólo dos argumentos: el tercero, que examinamos a continuación, y el cuarto.

En el tercero la voluntariedad de tales acciones se prueba en base al motivo de que siempre es posible escoger sufrir aquellos dolores y llevar a cabo aquellas acciones (1225 a 2-8). Por lo tanto, el no hacerlo es voluntario. Se trata exactamente de la reedición de la primera prueba aducida en Eth. nic., III, 1 (1110 a 13-15), presentada en su núcleo teoremático de fondo.

En el cuarto argumento (1225 a 8-19), Aristóteles, mientras confirma de nuevo la naturaleza voluntaria de las acciones sometidas a examen, desarrolla y profundiza eso que se decía en Eth. nic., III, 1 a propósito de su carácter mixto a través de las nociones de lo involuntario en sentido relativo y absoluto. Éstas representan, de hecho, la novedad doctrinal de la Ética eudemia, cuyo análisis

\footnotetext{
${ }^{6}$ Cfr. supra.
} 
sobre esta cuestión concreta no sólo plantea el problema en términos más esencializados respecto a la Ética nicomáquea, sino que plantea además la solución en términos más decisivos, por cuanto éstos abordan el fondo de la cuestión, resolviéndola desde la raíz. De hecho, el Estagirita precisa que, sobre la base de la determinación misma de la involuntariedad obtenido a partir del análisis de la idea de fuerza ( $\left.\beta^{\prime} \alpha\right)$, (a) son voluntarias las acciones que dependen del sujeto y que éste lleva a cabo incluso no queriendo llevarlas a cabo; (b) por el contrario son forzosas y, por lo tanto, involuntarias, aquéllas que no dependen del sujeto y que éste lleva a cabo (es forzado a llevarlas a cabo) con vistas a otras más importantes. Ahora bien, esta segunda acción es, en efecto, forzosa, pero no en sentido absoluto: son forzosas, por cuanto no se elige deliberadamente, pero no en absoluto, porque buscan la realización de otro objetivo más importante: evitar un mal mayor y más doloroso.

Del mismo modo, también el mal cometido para obtener un bien mayor o para liberarse de un mal mayor es involuntario, porque no es conforme a la naturaleza del que actúa, pero no en sentido absoluto, pues aquél, en cierto sentido, no depende del sujeto.

Desde esta perspectiva tales acciones son involuntarias (por cuanto hay fuerza en el sentido anteriormente precisado); también los males naturales, en el supuesto de que fuerzan la naturaleza y no dependen del sujeto (1225 a 21).

Aristóteles precisa, finalmente, que algunos pensamientos y algunas pasiones, así como las acciones de acuerdo con aquéllos y éstas, no dependen del sujeto, como lo que se piensa y lo que se hace cuando se está poseído (1225 a 27-33).

\section{Conclusión}

Si, en comparación con las escasas indicaciones de la Ética nicomáquea sobre la involuntariedad por la fuerza, la mayor madurez doctrinal de la Ética eudemia se evidencia en el análisis más rico y profundo de la cuestión, en el tratamiento de la involuntariedad por ignorancia, la Ética eudemia revela —al menos en una primera lectura - su datación más tardía y su superioridad conceptual respecto a la Ética nicomáquea por el carácter sintético y la esencialidad de su contenido: carácter sintético, en cuanto muestra claramente conocer y retomar los trazos 
básicos de esta última, algo que demuestra suficientemente la comparación entre los modos según los cuales en cada una de las obras se expone la cuestión; carácter esencial, en cuanto se concentra sólo en los elementos estrictamente inherentes a la determinación de la involuntariedad de una acción, obviando otras indicaciones que, por el contrario, sí encontramos en la Ética nicomáquea, y que, si bien son interesantes, tienen una relevancia menor o, en todo caso, tienen carácter de añadido a un concepto ya definido de otro modo.

Me refiero en particular (aunque no únicamente) a la indicación relativa a la ignorancia de la regla general de conducta, a la cual se refiere la Ética nicomáquea, pero no así la Ética eudemia: sin duda es verdad que aquélla, precisando qué tipo de ignorancia no comporta la involuntariedad de la acción, intenta aclarar ulteriormente ab extrinseco cuándo la ignorancia determina esta situación; pero es también verdad que esta misma situación está ya definida claramente a partir de la indicación específica y determinada de las que son las condiciones particulares de la acción a determinar, debiendo sancionarse, cuando éstas sean ignoradas, la involuntariedad; una indicación, en efecto, que es tanto más clara en sí misma cuanto ve enunciadas cuáles son tales condiciones de modo específico y determinado, individuándolas en el sujeto agente, en la acción llevada a cabo, en el medio según el cual se lleva a cabo, en el modo de llevarla a cabo y en el fin que busca.

Así dice, de hecho, Aristóteles en Eth. nic., III, 2, 1110 b 32 - b 6:

pues la ignorancia en la elección no es causa de lo involuntario sino de la maldad, como tampoco lo es la ignorancia universal (pues ésta es censu-

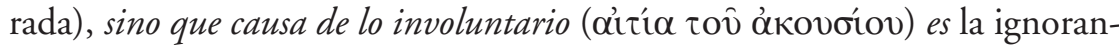
cia con respecto a las circunstancias concretas y al objeto de la acción (

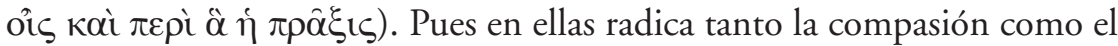
perdón, puesto que el que desconoce alguna de ellas actúa involuntariamente. No estaría mal, entonces, determinar cuáles y cuántas son, quién actúa y qué y acerca de qué o en qué, a veces también con qué, por ejemplo, con qué instrumento y por qué causa, por ejemplo, de la salvación, y cómo actúa, por ejemplo, serena o violentamente.

A continuación, a modo de refuerzo, sigue una serie de ejemplos cuyo objetivo es ilustrar, gracias a los episodios relativos a personajes y situaciones famosas, las circunstancias señaladas (1111 a 6-16). 
Después el estagirita precisa que para que una acción pueda considerarse involuntaria no es necesario que se ignoren todas las circunstancias en las que la misma se especifica, sino que basta con que se ignore «cualquiera de ellas ( $\tau o v ́ \tau \omega v$

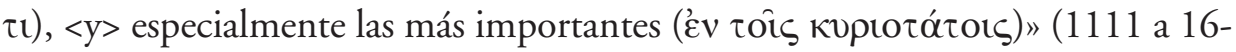
18), y aclara que, según el parecer unánime,

las <condiciones> más importantes se consideran las circunstancias de

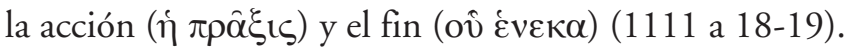

Anteriormente Aristóteles había apuntado que

obrar por ignorancia ( $\delta$ ’ ó $\gamma v o t \alpha v)$ parece cosa distinta del obrar con ignorancia ( $\alpha \gamma v o v \hat{v} \tau \alpha$ ): pues el embriagado o el encolerizado no parecen obrar por ignorancia ( $\delta$ i ó $\gamma v o t \alpha v$ ), sino por alguna de las causas mencionadas, no a sabiendas sino con ignorancia ( $\alpha \gamma v o \omega ̂ v)$. Pues todo malvado desconoce lo que debe hacer y de lo que debe apartarse, y por tal falta son injustos $y$, en general, malos. Ahora, el término «involuntario» tiende a ser usado no cuando alguien desconoce lo conveniente (1110 b 25-31).

Así definida en Eth. nic., III, 2 la involuntariedad de la acción debida a la ignorancia, teniendo también presente la primera condición de la involuntariedad, establecida en Eth. nic., III, 1, en Eth. nic., III, 3 Aristóteles define, por oposición, cuándo la acción es voluntaria, especificando, como hemos tenido ocasión de indicar ya, que tal cosa se da cuando (a) su principio está en el sujeto agente, (b) que conoce las condiciones particulares en las que se desarrolla la acción.

Ahora bien, mucho más sobriamente y concentrándose simultáneamente en lo estrictamente esencial, es decir, sin olvidar nada en la brevedad del discurso con el que busca caracterizar la ignorancia como causa de la involuntariedad y, por consiguiente, dar la definición del carácter voluntario de la acción misma de

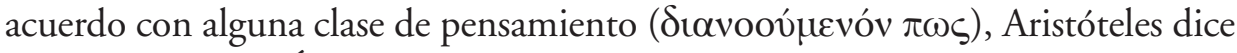
lo siguiente en la Ética eudemia:

Lo voluntario, así pues, parece ser opuesto a lo involuntario. Y obrar con conocimiento de la persona sobre quien se actúa, o del instrumento, o de la causa de la acción (algunas veces, en efecto, o bien uno sabe que es su padre, 
pero no < hace esto > para matarlo, sino para salvarlo, como las Pelíadas, o bien se sabe que es una bebida, como un filtro o vino, cuando realmente es cicuta) se opone a la ignorancia de la persona, del instrumento y del acto mismo, y esta ignorancia no es accidental; pero obrar por ignorancia del acto, del instrumento y de la persona, es una acción involuntaria. Luego, lo contrario es lo voluntario. Así pues, todo lo que un hombre hace - estando en su poder no hacerlo - sin estar en la ignorancia y por su propio esfuerzo, es necesariamente voluntario, y en esto consiste lo voluntario; pero todo lo que hace en la ignorancia y por causa de ella, lo hace involuntariamente (1225 b 2-10).

Aquí, como puede verse, con un razonamiento absolutamente riguroso Aristóteles (a) enuncia las mismas nociones de involuntariedad por ignorancia ( $\delta i$ ö $\gamma$ votav) y de voluntariedad de la acción en relación al conocimiento precisadas en la Ética nicomáquea; (b) especifica las mismas condiciones señaladas en la Ética nicomáquea como causas de la involuntariedad de la acción y, en ese sentido, las condiciones cuyo conocimiento determina el carácter voluntario de la misma; (c) al igual que en la Ética nicomáquea propone además, como ilustración, ejemplos de tales condiciones. Las nociones de voluntariedad e involuntariedad del actuar en relación al conocimiento son, por lo tanto, tanto en el uno como en el otro tratado idénticamente establecidas en cuanto a su contenido doctrinal. Sin embargo, en la Ética eudemia (d) Aristóteles establece con un único razonamiento, según la lógica de lo opuesto, las mismas nociones de voluntariedad e involuntariedad precisadas según la misma lógica en la Ética nicomáquea, si bien en dos lugares y dos momentos distintos; (e) no se extiende tampoco, como sucede en la Ética nicomáquea, en ilustrar lo irrelevante de la ignorancia de las reglas generales de conducta respecto a la involuntariedad del actuar mismo, ni, por consiguiente, se extiende en la distinción entre actuar "por ignorancia $(\delta t$

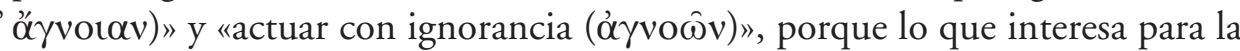
cuestión queda ya claro con la determinación del primer concepto, (f) mostrando, por otra parte, conocer tal distinción, y trayéndola a colación explícitamente, si bien mediante una simple alusión, allí donde dice «todo lo que hace en la ignorancia ( $\dot{\alpha} \gamma$ vốv) y por causa de ella ( $\delta \dot{\alpha} \alpha \gamma v o \varepsilon \hat{\imath} v) »(1225$ b 10). De donde, a la perfecta identidad doctrinal, evidenciada en las tres primeras observaciones, la Ética eudemia añade tanto la esencialidad del análisis, como puede comprobarse en las observaciones (d) y (e), como el conocimiento de los desarrollos paralelos de la Ética nicomáquea, a la que se apunta en la observación (f). 
Pero hay aún más. Puede encontrarse una precisión —conceptual y doctrinal a la vez- de la que no hay rastro en la Ética nicomáquea. Tal precisión concierne al conocimiento $-\mathrm{y}$, consiguientemente, también a la ignoranciade las mismas condiciones particulares de la acción. Pues — aclara Aristóteles- saber y conocer se dicen en dos sentidos: como simple posesión del cono-

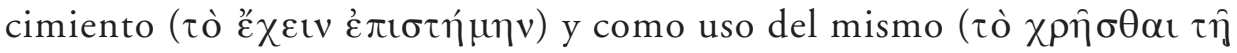
$\dot{\varepsilon} \pi \imath \tau \tau \eta \dot{\mu}$ ), y está claro que conocer (o ignorar) en el primer sentido las condiciones particulares de la acción no especifica la voluntariedad (o la involuntariedad), sino que ésta, así como la involuntariedad se determinan por el conocer o el ignorar en el segundo sentido las ya mencionadas condiciones (1225 b 11-16). Se trata, en este sentido, de un tratamiento verdaderamente más completo de la cuestión del conocimiento como causa de la voluntariedad o la involuntariedad de la acción, es decir, de la misma determinación del contenido acerca del cual se desarrolla la investigación en las dos obras. Tratamiento más completo que, por lo tanto, junto a la sobriedad y la esencialidad de los análisis, demuestra el mayor nivel de madurez alcanzado por Aristóteles en la Ética eudemia.

\section{Bibliografía}

\section{Ediciones}

Aristotle (1935, reimpr. 1981). The Athenian constitution; The Eudemian ethics; On virtues and vices, with an English translation by $\mathrm{H}$. Rackam, Cambridge, Mass., Harvard University press, London, Heinemann.

Aristotelis (1967). Ethica Eudemia, adiecto de virtutibus et vitiis libello, recognovit Fr. Susemihl, editio stereotypa, Amsterdam, Verlag A. M. Hakkert.

Aristotelis (1991). Ethica Eudemia, recognoverunt brevique adnotatione critica instruxerunt R. R. Walzer et J. M. Mingay, Praefatione auxit J. M. Mingay, Oxford, Clarendon University Press.

\section{Traducciones}

Aristoteles (1994). Ética Eudemia, versión de A. Gómez Robledo, Universidad Nacional Autónoma de México, Ciudad Universitaria. 
Aristóteles (1985). Ética Nicomáquea y Ética eudemia, introducción de E. Lledó Íñigo, traducción y notas de J. Pallí Bonet, revisión de Q. Racionero Carmona, Madrid, Editorial Gredos (la Ética eudemia comprende las pp. 411-547).

Aristóteles (2005). Ética eudemia, versión de C. Megino Rodríguez, Clásicos de Grecia y Roma, 8250, Alianza Editorial.

\section{Trabajos de investigación}

AA. VV. (1960). Aristote et les problèmes de méthode, Communications présentées au Symposium aristotelicum tenu à Louvain du 24 août au $1^{\text {er }}$ septembre $1960,2^{\text {ème }}$ édition, Louvain-La-Neuve, Éditions de l'Institut Superieur de Philosophie.

AA. VV. (1971). Untersuchungen zur Eudemischen Ethik, Akten des V Symposium Aristotelicum (Oosterbeek, Niederlande, 21-29 August 1969), herausgegeben von P. Moraux und D. Harlfinger, Berlin, Walter De Gruyter.

AA. VV. (1990). Studi sull'Etica di Aristotele, a cura di A. Alberti, Napoli, Bibliopolis.

AA. VV. (2002). L'excellence de la vie: sur l'Éthique à Nicomaque et l'Éthique à Eudème, études sous la direction de G. Romeyer Dherby, réunies et éditées par G. Aubry, Paris, Vrin.

AA. VV. (2008). Analyse comparative des vertus morales particulières dans l'Éthique à Nicomaque et l'Éthique à Eudème, par L. Rodrigue, Université de Montréal.

Alberti, A. (1990). «Philia e identità personale in Aristotele», en AA. VV., Studi sull'Etica di Aristotele, op. cit., pp. 263-302.

Allan, D. J. (1960). "Quasi-mathematical method in the Eudemian Ethics», en AA. VV., Aristote et les problèmes de méthode, op. cit., pp. 303-318.

Allan, D. J. (1963-64). "Aristotle's criticism of Platonic doctrine concerning goodness and the God», Proceedings of the Aristotelian Society, pp. 273-286.

Allan, D. J. (1971). "The fine and the good in the Eudemian Ethics», en AA. VV., Untersuchungen zur Eudemischen Ethik., op. cit., pp. 63-72.

BERTI, E. (1971). «Multiplicité et unité du bien selon EE I 8», en AA. VV., Untersuchungen zur Eudemischen Ethik., op. cit., pp. 157-184.

BERTI, E. (1989). Le ragioni di Aristotele, Roma-Bari, Laterza.

BERTI, E. (1990). «Il metodo della filosofia pratica in Aristotele», en AA. VV., Studi sull'Etica di Aristotele, op. cit., pp. 23-64.

Broadie, S. (2007). Aristotle and beyond: essays on metaphysics and ethics, Cambridge, Cambridge University Press. 
BroAdie, S. (1991). Ethics with Aristotle, New York and Oxford, Oxford University Press.

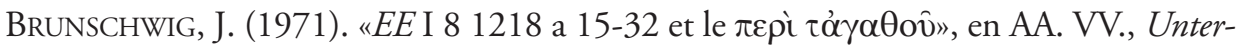
suchungen zur Eudemischen Ethik., op. cit., pp. 197-222.

BuddensieK, F. (1999). Die Theorie des Glücks in Aristoteles Eudemischer Ethik, Göttingen, Vandenhoeck \& Ruprecht.

Cherniss, H. (1944, 1962). Aristotle's criticism of Plato and Academy, Baltimore, New York.

Dirlmeier, F. (1962). Merkwürdige Zitate in der Eudemischen Ethik des Aristoteles, Heidelberg, C. Winter Verlag.

DÜRING, I. (1966). Aristoteles. Darstellung und Interpretation seines Denkens, Heidelberg, Winter.

Flashar, H. (1965). «Die Kritik der platonischen Ideenlehre in der Ethik des Aristoteles», en Flashar H.-Gaiser K., Synusia, Festgabe für Wolfang Schadewaldt, Paderbon, pp. 223-246.

Fragstein, A. (1974). Studien zur Ethik des Aristoteles, Amsterdam.

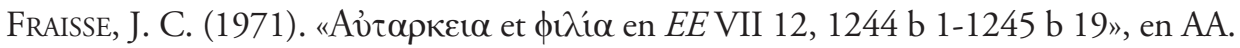
VV., Untersuchungen zur Eudemischen Ethik., op. cit., pp. 245-252.

GAISER, K. (1967). «Zwei Protreptikos-Zitate in der Eudemische Ethik des Aristoteles», Rheinisches Museum für Philologie 110, pp. 314-345.

Gigon, O. (1971). «Das Proomion der Eudemischen Ethik», en AA. VV., Untersuchungen zur Eudemischen Ethik., op. cit., pp. 93-134.

HARLFINGER, D. (1971). «Überlieferungsgeschichte der Eudemischen Ethik», en AA. VV., Untersuchungen zur Eudemischen Ethik., op. cit., pp. 1-50.

JAEGER, W. (1923). Aristoteles. Grundlegung einer Geschichte seiner Entwicklung, Berlin.

JACKSON, H. (1912). «Eudemian ethics 1246 a 26 - 1248 b 8», The Journal of Philology.

Kenny, A. J. P. (1978). The Aristotelian ethics: a study of the relationship between the 'Eudemian' and 'Nicomachean ethics' of Aristotle, Oxford, Clarendon Press.

Kenny, A. J. P. (1992). Aristotle on the perfect live, Oxford, Clarendon Press.

KIRWAN, CH. (1990). "Two aristotelian theses about eudaimonia», en AA. VV., Studi sull'Etica di Aristotele, op. cit., pp. 149-192.

Kosman, L. A. (1968). «Predicating the Good», Phronesis 13, pp. 171-174.

Kraut, R. (1989). Aristotle on the human good, Princeton, Princeton University Press.

LESZL, W. (1971). «Ricerche sull'Etica eudemia», Rivista di Filosofia Neoscolastica 63. 
LESZL, W. (1990). "Alcune specificità del sapere pratico in Aristotele», en AA. VV., Studi sull'Etica di Aristotele, op. cit., pp. 65-118.

MingaY, D. J. (1971). «Some controversial passages in the Eudemian Ethics», en AA. VV., Untersuchungen zur Eudemischen Ethik., op. cit., pp. 51-62.

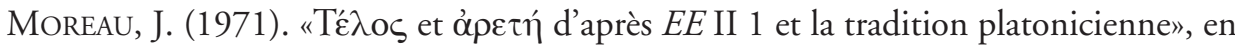
AA. VV., Untersuchungen zur Eudemischen Ethik., op. cit., pp. 223-230.

NATALI, C. (1989). La saggezza in Aristotele, Napoli, Bibliopolis.

Natali, C. (1997). «Etica», en AA. VV., Guida ad Aristotele, a cura di E, Berti, RomaBari, Laterza, pp. 241-282.

Natali, C. (2008). «L'amicizia secondo Aristotele», Bollettino della Società Filosofica Italiana 195, pp. 13-28.

Owen, G. E. L. (1960, 1979). «Logic and metaphysics in some earlier works of Aristotle», en AA. VV., Aristotle and Plato in the mid-fourth century, hrsg. von I. Düring, Göteborg, 1960, pp. 163-190; ahora en AA. VV., Articles on Aristotle, vol. VII: Metaphysics, edited by J. Barnes, M. Schofield, R. Sorabgji, London, 1979, pp. 13-32.

REES, D. A. (1971). «Magnanimity in the Eudemian and Nicomachean Ethics», en AA. VV., Untersuchungen zur Eudemischen Ethik., op. cit., pp. 231-244.

Robinson, D. B. (1971). "Ends and means and logical priority», en AA. VV., Untersuchungen zur Eudemischen Ethik., op. cit., pp. 185-194.

Ross, D. (1923). Aristotle, London.

Rowe, C. (1971). The Eudemian and Nicomachean ethics: a study in the development of Aristotele's thought, Cambridge, Cambridge Philological Society, supplementary volumes 3 .

Rowe, C. J. (1971). "The meaning of phronesis in the Eudemian Ethics», en AA. VV., Untersuchungen zur Eudemischen Ethik., op. cit., pp. 73-92.

Trabattoni, F. (2009). "L'etica di Aristotele è eudemonistica?», en AA. VV., Attività e virtù: anima e corpo in Aristotele, a cura di A. Fimiani e M. Migliori, Milano, Vita e Pensiero, pp. 449-468.

VerbeKe, G. (1971). "La critique des idées dans l'Étique Eudémienne», en AA. VV., Untersuchungen zur Eudemischen Ethik., op. cit., pp. 135-156.

VerdeniUs, W. J. (1971). "Human reason and God in the Eudemian Ethics», en AA. VV., Untersuchungen zur Eudemischen Ethik., op. cit., pp. 285-298.

Von Arnim, H. F. A. (1928). Eudemische Ethik und Metaphysik, Sitzungsberichte der Akademie der Wissenschaften in Wien, Philosophisch-historische Klasse, 207/5, Wien, Leipzig, Hölder Pichler Tempsky. 
Woods, M. (1990). «Aristotle on akrasia», en AA. VV., Studi sull'Etica di Aristotele, op. cit., pp. 227-262.

ZanatTa, M. (2010). Introduzione alla filosofia di Aristotele, Milano, Rizzoli.

Recibido: 28/06/2011

Aceptado: 25/11/2011 
